\title{
Unprecedented use of silver(I) N-heterocyclic carbene complexes for the catalytic preparation of 1,2-bis(boronate) esters
}

\author{
Jesus Ramírez, ${ }^{a}$ Rosa Corberán, ${ }^{b}$ Mercedes Sanaú, ${ }^{c}$ Eduardo Peris ${ }^{* b}$ and Elena Fernandez ${ }^{* a}$ \\ Received (in Cambridge, UK) 4th March 2005, Accepted 14th April 2005 \\ First published as an Advance Article on the web 6th May 2005 \\ DOI: $10.1039 / \mathrm{b503239c}$
}

Catalytic diboration of internal and terminal alkenes with $\mathrm{Ag}(\mathrm{I})$ N-heterocyclic carbene complexes leads to 1,2-bis(boronate) esters as single intermediates, that can be oxidised towards the corresponding diols.

Transition metal complexes play an important role in the diboration reaction, allowing the introduction of two functional groups into an organic molecule at a time. ${ }^{1,2}$ According to the catalytic cycle proposed, ${ }^{3}$ insertion of the metal complex into the $\mathrm{B}-\mathrm{B} \sigma$ bond of stable alkoxo diboranes ${ }^{4,5}$ occurs, yielding a metaldiboryl intermediate which determines the chemo- (diboration versus hydroboration) and enantioselectivity when reacting with alkenes (Scheme 1). Thus, the design of proper catalysts that selectively provide 1,2-bis(boronate) esters (1) is one of the main challenges in this catalytic reaction. ${ }^{6}$

While cationic rhodium(I) complexes with chiral P,N-bidentate ligands (Quinap) allow enantioselective addition of bis(catecholatodiboron) to alkenes, ${ }^{6}$ chemoselectivity becomes very low due to the inherent competitive $\beta$-H-elimination that provides alkyl-, 2ab, and alkenylboronate ester, 3. Alternatively, gold(I)-diphosphine catalytic systems improve chemoselectivity towards the desired 1,2bis(boronate) ester 1, although catalyst activity and stability remain lower than desired. ${ }^{3}$ Finally, base-free Pt systems also

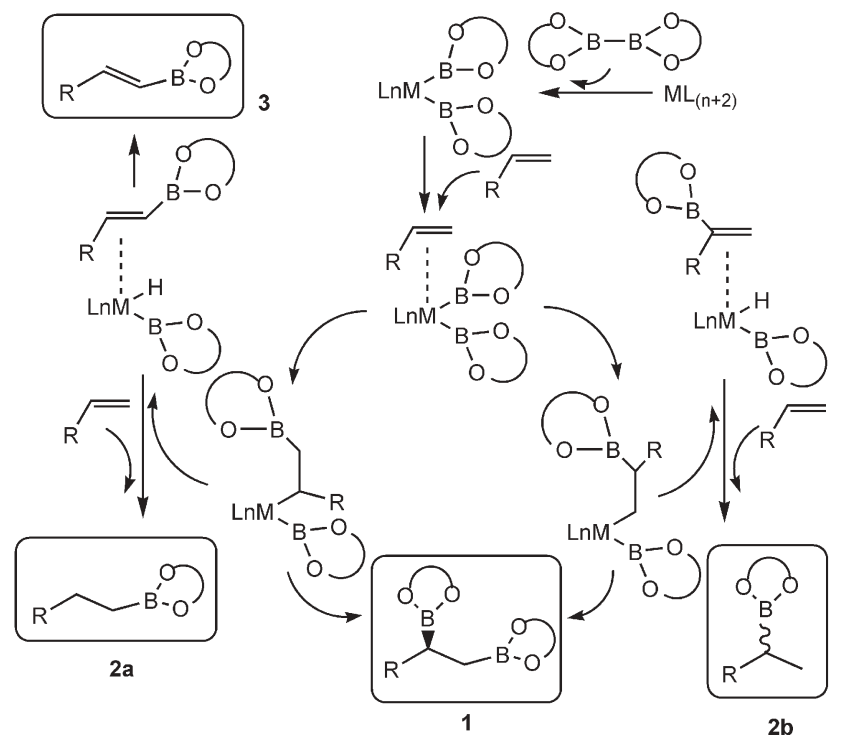

Scheme 1 contribute to clean diboration, but the scope of the reaction is not general to internal and terminal alkenes and they are not appropriate for modification with chiral ligands. ${ }^{7,8}$

With the aim of avoiding competitive $\beta$-hydride elimination we thought that cationic silver(I) complexes with N-heterocyclic carbenes could be good candidates. These complexes combine enough electron richness to guarantee B-B cleavage of the diborane, with low energy $d$-orbitals that minimize $\pi$-backbonding and thus $\beta$-elimination.

$\mathrm{N}$-heterocyclic carbenes (NHC) have emerged as a promising family of ligands that can be used in the design of efficient homogeneous catalysts. ${ }^{9}$ The structural diversity of silver(I) $\mathrm{N}$-heterocyclic carbenes has been studied in a number of papers, ${ }^{10-12}$ and their application as carbene transferring agents has widened their use as an easy access to various important metal NHC-complexes. ${ }^{11,13,14}$ However, despite the number of silver $\mathrm{NHC}$ complexes reported to date we have no knowledge of these being applied in catalytic processes.

Based on our previous experience, we now report the synthesis and catalytic properties of a new NHC-complex of $\mathrm{Ag}(\mathrm{I})$. With the aim of obtaining a sterically hindered complex that could help us to provide high stereoselectivity in the diboration reaction, we decided to use 1-methyl-3-(+)-methylmenthoxide imidazolium chloride as the precursor of the N-heterocyclic carbene. $\uparrow$

1-Methyl-3-(+)-methylmenthoxide imidazolium chloride (mentimidH) was obtained by direct reaction of $N$-methylimidazole and (+)-chloromethyl menthyl ether. The reaction is performed at room temperature in the absence of solvent, yielding a white solid in high yield ( $c a .92 \%)$. The resulting imidazolium salt was characterized by ${ }^{1} \mathrm{H}$ NMR and ${ }^{13} \mathrm{C} N M R$ spectroscopy.

The addition of the chiral imidazolium chloride to a suspension of an excess of $\mathrm{Ag}_{2} \mathrm{O}$ in $\mathrm{CH}_{2} \mathrm{Cl}_{2}$ afforded the isolation of $\left.[\text { (mentimid })_{2} \mathrm{Ag}\right] \mathrm{AgCl}_{2}, \mathbf{4}$, after workup (Scheme 2).

Compound 4 was characterized by NMR and mass spectroscopy.t The signals of the protons of the imidazolylidene ring

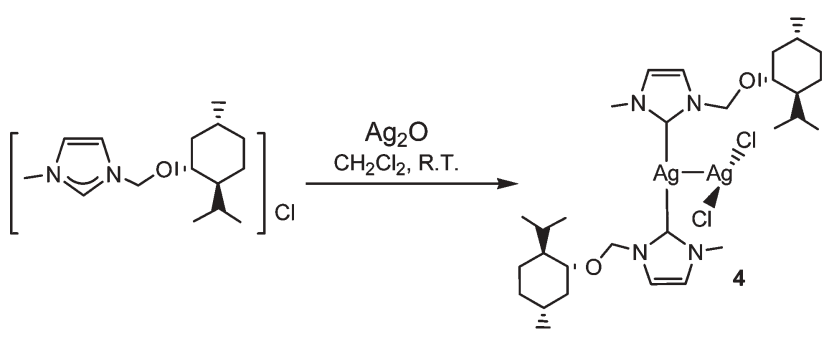


appear at 7.2 and $7.0 \mathrm{ppm}$. The ${ }^{13} \mathrm{C}$ NMR spectrum reveals that coordination of the NHC has occurred, as shown by the signal at 180.8 ppm, typical of a metallated Ag-NHC bond. ${ }^{11,12}$

Crystals of $\mathbf{4}$ suitable for X-ray diffraction were obtained from concentrated $\mathrm{CH}_{2} \mathrm{Cl}_{2}$ /hexane solutions, and the results confirmed the structure proposed. Fig. 1 shows the ORTEP diagram of $\mathbf{4}$ and the more representative bond distances and angles. The molecule crystallizes in the non-centrosymmetric space group $P 1$. The compound consists of two linear $\left[(\text { mentimid })_{2} \mathrm{Ag}\right]^{+}$intercalating a $\left[\mathrm{Ag}_{2} \mathrm{Cl}_{4}\right]^{2-}$ anion, thus providing a weak $\mathrm{Ag}$ (cation) $\cdots \mathrm{Ag}$ (anion) attraction. These two ions associate through a close contact $\mathrm{Ag}$ Ag interaction of $2.9 \AA$, similar to that shown for other $\mathrm{Ag}-\mathrm{NHC}$ structures. ${ }^{11,13}$ The Ag-C distance is $2.1 \AA$.

Bis(catecholato)diboron was added to internal and terminal alkenes in presence of the precursor of catalyst 4 ( $5 \mathrm{~mol} \%)$, under optimised reaction conditions (room temperature in THF). The resulting diborane compound was oxidised to the corresponding diol in presence of $\mathrm{NaOH} / \mathrm{H}_{2} \mathrm{O}_{2} .{ }^{1} \mathrm{H} \mathrm{NMR}$ and $\mathrm{GC}$ of the ketal derivative allowed us to determine the conversion and selectivity of the catalytic reaction. Among the terminal alkenes, we observed that the diboration/oxidation of styrene with $\mathbf{4}$ provided the single product 1-phenyl-1,2-ethanediol with $76 \%$ conversion (Table 1, entry 1). Isolated compound 4 showed a much higher catalytic activity than when prepared in situ from $\mathrm{Ag}_{2} \mathrm{O}$ and the imidazolium chloride, that only showed conversions of about $5 \%$. When the reaction was carried out at $70{ }^{\circ} \mathrm{C}$ we observed an unusually slow transformation towards the desired product, although $\beta$-H-elimination was not competitive even under these reaction conditions (Table 1, entry 2). The electron-accepting substituted vinylarenes proved to be less reactive than styrene (Table 1, entries 3-5). On the other hand, the more electron-rich vinyl-cyclohexane was by far the most active substrate in terms of conversion into the corresponding diol (Table 1, entry 6). A similar trend has been described in the diboration of para-substituted terminal phenylacetylenes with $\operatorname{Pt}(0)$ catalytic complexes where electron withdrawing substituents diminish the reaction rates. ${ }^{15}$ Remarkably, the hindered internal alkene indene was able to be cleanly transformed to the desired product, although with a low conversion (Table 1, entry 7).

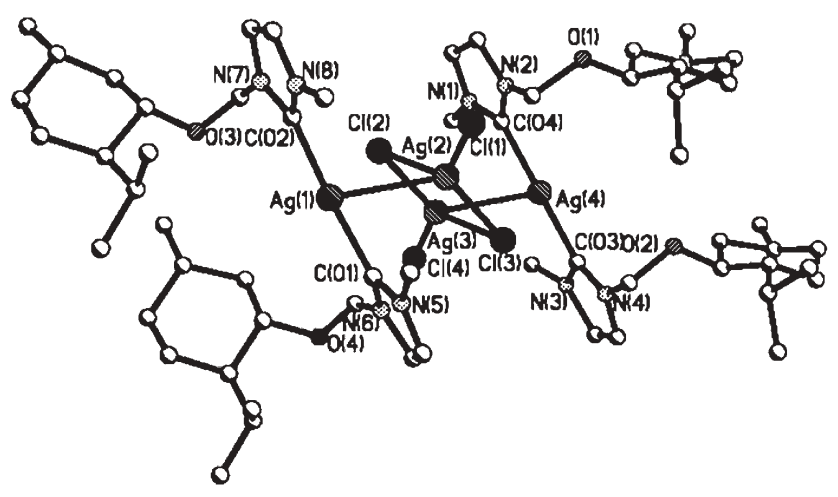

Fig. 1 X-Ray crystal structure of $\left[(\text { mentimid })_{2} \mathrm{Ag}\right] \mathrm{AgCl}_{2}$. Selected bond distances $(\AA)$ and angles $\left({ }^{\circ}\right)$ : $\operatorname{Ag}(1)-\operatorname{Ag}(2)$ 2.952(2), $\operatorname{Ag}(3)-\operatorname{Ag}(4)$ 2.942(2), $\mathrm{Ag}(1)-\mathrm{C}(01)$ 2.104(18), $\mathrm{Ag}(1)-\mathrm{C}(02)$ 2.09(2), C(02)-Ag(1)-C(01) 168.7(7), $\mathrm{C}(04)-\mathrm{Ag}(4)-\mathrm{C}(03)$ 175.6(10), $\mathrm{Cl}(2)-\mathrm{Ag}(2)-\mathrm{Cl}(3)$ 95.12(19), $\mathrm{Cl}(2)-\mathrm{Ag}(3)-$ $\mathrm{Cl}(3)$ 94.74(19).
Table 1 (mentimid $\left.)_{2} \mathrm{Ag}\right] \mathrm{AgCl}_{2}$ catalysed diboration/oxidation of alkenes with bis(catecholato)diboron ${ }^{a}$

Entry Substrate Conv. (\%) Diol (\%)

${ }^{a}$ Standard conditions: alkene/diborane/Ag complex $4=0.5 / 0.55 /$ 0.025. Solvent: THF. T: $25{ }^{\circ} \mathrm{C}, 60 \mathrm{~h} .{ }^{b}$ Determined by ${ }^{1} \mathrm{H}$ NMR before oxidation. ${ }^{c}$ Determined by GC with chiral column FSCyclodex B-IP, $50 \mathrm{~m} \times 0.25 \mathrm{~mm}$ of the ketal derivatives. ${ }^{d}$ Reflux at $70{ }^{\circ} \mathrm{C}, 20 \mathrm{~h}$.

Despite the use of our chiral imidazolylidene ligand we did not observe any asymmetric induction on the reaction products, presumably because the chiral center lies far from the metal. In addition, the lability of the $\mathrm{Ag}-\mathrm{C}_{\text {carbene }}$ bond could favour some equilibrium between [(mentimid $\left.)_{2} \mathrm{Ag}\right] \mathrm{AgCl}_{2}$ and $[($ mentimid $) \mathrm{AgCl}],{ }^{10}$ thus making it difficult to establish which is the real catalytic species. Alternatively, the use of chiral diboranes ${ }^{16}$ such as bis(diethyl-) and bis(diisopropyl-D-tartrateglycolato)diboron and bis((+)-pinanediolato)diboron resulted in a total inhibited diboration reaction, making bis(catecholato)diboron the specific diborating reagent for this reaction with 4 .

The results of this study indicate that the new thermally and airstable compound [(mentimid $\left.)_{2} \mathrm{Ag}\right] \mathrm{AgCl}_{2}$ cleanly catalyses the diboration of alkenes with bis(catecholato)diboron. It is noteworthy that we performed the same reaction with analogous $\mathrm{Ag}(\mathrm{I})$ complexes modified with phosphines (and diphosphines), ${ }^{17}$ but they did not allow any conversion of the alkenes towards the desired diborated products, under the same reaction conditions. Even $\mathrm{AgNO}_{3}$ was tested in this reaction to study the possible participation of the ion $\mathrm{Ag}^{+}$as the catalytic species, but no reactivity was monitored.

In conclusion, this is the first time that catalytic diboration has been carried out with $\operatorname{Ag}(\mathrm{I})$ complexes. Furthermore, to our 
knowledge, this is also the first example of an NHC-complex of $\mathrm{Ag}(\mathrm{I})$ being used in a catalytic process.

Additional improvements in the design of an asymmetrically inductive $\mathrm{Ag}-\mathrm{NHC}$ catalytic system are in progress and may bring the reaction to the point where it becomes competitive with other methods for this chemical synthesis.\$

The authors thank the CTQ2004-04412/BQU and the CICYT (MAT2002-04421-C02-01) for financial support. J.R. thanks the Generalitat de Catalunya for a fellowship.

\section{Jesus Ramírez, ${ }^{a}$ Rosa Corberán, ${ }^{b}$ Mercedes Sanaú, ${ }^{c}$ Eduardo Peris ${ }^{* b}$} and Elena Fernandez $* a$

${ }^{a}$ Departament de Química Física i Inorgànica, Universitat Rovira $i$ Virgili, Pça. Imperial Tàrraco 1, 43005, Tarragona, Spain.

E-mail: elenaf@quimica.urv.es; Fax: 34977 559563; Tel: 34977558046

${ }^{b}$ Dpt. Química Inorgànica i Orgànica, Universitat Jaume I, Av Vicente Sos Baynats/n, 12080, Castellón, Spain.E-mail: eperis@qio.uji.es

${ }^{c}$ Dpt. Química Inorgánica, Universitat de València, 46100, Burjassot, Spain

\section{Notes and references}

$\uparrow$ Synthesis of 1-methyl-3-(+)-methylmenthoxide imidazolium chloride: (+)-chloromethyl menthyl ether $(1.1 \mathrm{~mL}, 5 \mathrm{mmol})$ was added to $\mathrm{N}$-methylimidazole $(0.4 \mathrm{~mL}, 5 \mathrm{mmol})$ at room temperature with the ready precipitation of a white solid. The solid was purified by precipitation with $\mathrm{CH}_{2} \mathrm{Cl}_{2}$ /ether. Yield: $1.315 \mathrm{~g}(92 \%) .{ }^{1} \mathrm{H} \mathrm{NMR}\left(\mathrm{CDCl}_{3}, 500 \mathrm{MHz}\right)$ (menthyl signals omitted): $11.07(\mathrm{~s}, 1 \mathrm{H}, \mathrm{NCHN}), 7.43(\mathrm{~s}, 1 \mathrm{H}$, imidazole-H), $7.41(\mathrm{~s}$, $1 \mathrm{H}$, imidazole- $\mathrm{H}), 5.89\left(\mathrm{~d}, 1 \mathrm{H},-\mathrm{CH}_{a} \mathrm{H}_{\mathrm{b}}-\mathrm{O}\right), 5.66\left(\mathrm{~d}, 1 \mathrm{H},-\mathrm{CH}_{\mathrm{a}} \mathrm{H}_{b}-\mathrm{O}\right), 4.12$ (s, $3 \mathrm{H}, \mathrm{CH}_{3}$-imidazole). ${ }^{13} \mathrm{C}$ NMR (DMSO- $d_{6}$ ) (menthyl and $\mathrm{CH}_{3-}$ imidazole signals omitted): 138.00 (s, NCHN), 124.66 (s, imidazole), 122.93 (s, imidazole), 78.24 (s, $\left.-\mathrm{CH}_{2}-\mathrm{O}\right) . \alpha=+0.5538^{\circ}$.

* Synthesis of $\left.[\text { (mentimid })_{2} \mathrm{Ag}\right] \mathrm{AgCl}_{2}, 4$. Silver oxide $(121 \mathrm{mg}, 0.5 \mathrm{mmol})$ was added to a solution of 1-methyl-3-(+)-methylmenthoxide imidazolium chloride $(200 \mathrm{mg}, 0.7 \mathrm{mmol})$ in $10 \mathrm{~mL}$ of dichloromethane. The mixture was stirred at room temperature for $4 \mathrm{~h}$ and then filtered through Celite. The solvent was eliminated under vacuum and the resulting solid was the pure compound 2-Ag. Yield: $200 \mathrm{mg}(84 \%) .{ }^{1} \mathrm{H}$ NMR $\left(\mathrm{CDCl}_{3}, 300 \mathrm{MHz}\right)$ (menthyl signals omitted): 7.18 (s, $1 \mathrm{H}$, imidazole- $\mathrm{H}), 7.02(\mathrm{~s}, 1 \mathrm{H}$, imidazole$\mathrm{H}), 5.52\left(\mathrm{~d}, 1 \mathrm{H},-\mathrm{CH}_{a} \mathrm{H}_{\mathrm{b}}-\mathrm{O}\right), 5.41\left(\mathrm{~d}, 1 \mathrm{H},-\mathrm{CH}_{\mathrm{a}} \mathrm{H}_{b}-\mathrm{O}\right), 3.85\left(\mathrm{~s}, 3 \mathrm{H}, \mathrm{CH}_{3^{-}}\right.$ imidazole). ${ }^{13} \mathrm{C}$ NMR $\left(\mathrm{CDCl}_{3}, 300 \mathrm{MHz}\right.$ ) (menthyl and $\mathrm{CH}_{3}$-imidazole signals omitted): 180.85 (s, C-Ag), 123.20 (s, imidazole), 121.18 (s, imidazole), 78.61 (s, $\left.-\mathrm{CH}_{2}-\mathrm{O}\right) . \alpha=+0.3022^{\circ}$. Electrospray MS. Cone $30 \mathrm{~V} . \mathrm{m} / \mathrm{z}$ (fragment): $609\left[\mathrm{AgL}_{2}\right]^{+}$.

$\S$ Crystal data for 4: $M=1574.79$, triclinic, space group $P 1, a=9.3318(19)$, $b=11.080(2), c=18.816(4) \AA, \alpha=105.54(3), \beta=97.78(3), \gamma=94.74(3)^{\circ}$, $V=1842.6(6) \AA^{3}, Z=1, D_{\mathrm{c}}=1.419 \mathrm{~g} \mathrm{~cm}^{-3}$, Mo-K $\alpha$ radiation $(\lambda=0.71073 \AA), 15440$ reflections collected, 12817 unique, observed reflections $(I>2.00 \sigma(I)), R=0.0601, R_{w}=0.1559$. CCDC 264639. See http://www.rsc.org/suppdata/cc/b5/b503239c/ for crystallographic data in CIF or other electronic format.

- Typical catalytic diboration of styrene: Bis(catecholato)diboron $(0.55 \mathrm{mmol})$ was added to a solution of catalyst $(5 \mathrm{~mol} \%, 0.025 \mathrm{mmol})$ in THF ( $2 \mathrm{ml})$ under argon. The solution was stirred for 5 minutes and styrene $(0.5 \mathrm{mmol})$ was then added. The mixture was stirred at ambient temperature for 60 hours, and the conversion was determined by ${ }^{1} \mathrm{H}$ NMR. CAUTION: Workup must be carried out carefully owing to the risk of explosion when using peroxides with THF. Afterwards, $\mathrm{NaOH}(3 \mathrm{M}$, $800 \mu \mathrm{L})$ and $\mathrm{H}_{2} \mathrm{O}_{2}(800 \mu \mathrm{L})$ were added and the mixture was stirred for 3 hours. After this time, $1 \mathrm{~mL}$ of saturated $\mathrm{Na}_{2} \mathrm{~S}_{2} \mathrm{O}_{3}$ was added, followed by $10 \mathrm{~mL}$ of $\mathrm{NaOH}(1 \mathrm{M})$. The reaction mixture was extracted into AcOEt $(3 \times 25 \mathrm{~mL})$ and washed with brine, dried over $\mathrm{MgSO}_{4}$, and the products were characterized by chromatography and ${ }^{1} \mathrm{H}$ NMR.

1 T. B. Marder and N. C. Norman, Top. Catal., 1999, 5, 63.

2 T. Ishiyama and N. Miyaura, Chem. Rec., 2004, 3, 271.

3 R. T. Baker, P. Nguyen, T. B. Marder and S. A. Westcott, Angew. Chem., Int. Ed. Engl., 1995, 34, 1336.

4 H. Nöth, Z. Naturforsch., Teil B, 1984, 39, 1463.

5 G. Lesley, T. B. Marder, N. C. Norman and C. R. Rice, Main Group Chem. News, 1997, 5, 4.

6 C. Dai, E. G. Robins, A. J. Scott, W. Clegg, D. S. Yufit, J. A. K. Howard and T. B. Marder, Chem. Commun., 1998, 1983; J. B. Morgan, S. P. Miller and J. P. Morken, J. Am. Chem. Soc., 2003, 125, 8702-8703.

7 T. Ishiyama, M. Yamamoto and N. Miyaura, Chem. Commun., 1997, 689.

8 C. N. Iverson and M. R. Smith, III, Organometallics, 1997, 16, 2757.

9 D. Bourissou, O. Guerret, F. P. Gabbai and G. Bertrand, Chem. Rev., 2000, 100, 39; K. J. Cavell and D. S. McGuinness, Coord. Chem. Rev., 2004, 248, 671; E. Peris and R. H. Crabtree, C. R. Chim., 2003, 6, 33; W. A. Herrmann, Angew. Chem., Int. Ed., 2002, 41, 1291; A. J. Arduengo, Acc. Chem. Res., 1999, 32, 913; E. Peris and R. H. Crabtree, Coord. Chem. Rev., 2004, 248, 2239.

10 I. J. B. Lin and C. S. Vasam, Comments Inorg. Chem., 2004, 25, 75.

11 K. M. Lee, H. M. J. Wang and I. J. B. Lin, J. Chem. Soc., Dalton Trans., 2002, 2852.

12 Y. A. Wanniarachchi, M. A. Khan and L. M. Slaughter, Organometallics, 2004, 23, 5881; A. Kascatan-Nebioglu, M. J. Panzner, J. C. Garrison, C. A. Tessier and W. J. Youngs, Organometallics, 2004, 23, 1928; P. L. Arnold, A. C. Scarisbrick, A. J. Blake and C. Wilson, Chem. Commun., 2001, 234

13 H. M. J. Wang and I. J. B. Lin, Organometallics, 1998, 17, 972

14 R. S. Simons, P. Custer, C. A. Tessier and W. J. Youngs, Organometallics, 2003, 22, 1979; A. R. Chianese, X. W. Li, M. C. Janzen, J. W. Faller and R. H. Crabtree, Organometallics, 2003, 22, 1663; J. A. Mata, A. R. Chianese, J. R. Miecznikowski, M. Poyatos, E. Peris, J. W. Faller and R. H. Crabtree, Organometallics, 2004, 23, 1253.

15 R. L. Thomas, F. E. S. Souza and T. B. Marder, J. Chem. Soc., Dalton Trans., 2001, 1650

16 T. B. Marder, N. C. Norman and C. R. Rice, Terahedron Lett., 1998, 39, 155; W. Clegg, T. R. F. Johann, T. B. Marder, N. C. Norman, A. G. Orpen, T. M. Peakman, M. J. Quayle, C. R. Rice and A. J. Scott, Dalton Trans., 1998, 1431.

17 N. Momiyama and H. Yamamoto, J. Am. Chem. Soc., 2004, 126, 5360; Ch. Chen, X. Li and S. L. Schreiber, J. Am. Chem. Soc., 2003, 125, 10174. 